\title{
The Application Research Of A New Superhydrophobic \& Anti-Corrosive Coating On Crude-Oil Pipeline
}

\author{
Zhou Jianwei ${ }^{1, \text { a }}$, Liu Zhe ${ }^{2}$, Tian Shengjie ${ }^{3}$, $\mathrm{Li} \mathrm{Hao}^{3}$, Xiao Jianghua ${ }^{3}$, Tang \\ Wenshu $^{3}$, ,Li Chunman ${ }^{1}$,Yang Fajie ${ }^{1}$, Chang Weichun ${ }^{1}$,Guo Haifeng ${ }^{1}$ \\ ${ }^{1}$ Petrochina Pipeline R\&D Center , Langfang, Hebei, China \\ ${ }^{2}$ Sinopec Pipeline Storage \& Transportation (Branch) Company, Xuzhou, Jiangsu, China \\ ${ }^{3}$ Petrochina Pipeline Company, Langfang, Hebei, China \\ azhoujianwei_6848@sina.com
}

Keywords: superhydrophobic coating, pipeline, condensate water, corrosive

Abstract. There is much condensate water formed on the surface of the pipeline carrying low temperature crude oil in Da Hinggan Ling Prefecture, because of the coefficient of the high relative humidity and the difference in temperature between the pipeline and air. In this article, a new superhydrophobic \& anti-corrosive coating was applied on the pipeline in MoHe pump station. The coating was prepared by cold zinc primer (with dry film zinc content over 93\%), micaceous iron oxide epoxy (with high ability of shielding water) and superhydrophobic finishes. Results showed that there was not any corrosive phenomenon visible to naked eye after 3 years of testing, while the former coating was failed in just 1 year.

\section{Introduction}

A two hierarchical Micro-Nano structure can be formed by the superhydrophobic coating. The structure is just like the surface of lotus leaf, and get the ability of self-cleaning. The mechanism of the lotus effect was first revealed by professor Barthlott[1] in Bonn University. There were many mastoids in Micro-class distributed uniformly on the lotus leaf, and a great number of wax flosses in Nano-class grown on each mastoids. As a result, the specific surface area was greatly improved, and the surface got superhydrophobic. Based on this principle, a lot of methods have been developed to prepare the superdydrophobic surface, such as template method[4-5], phase separation method[6], laser engraving and chemical etching method[7], organic-inorganic mixed method[8,9], sol-gel method[10], vapor deposition method[11-12] and so on.

China-Russia crude oil pipeline is $965 \mathrm{~km}$ long form MoHe to DaQing in China, and there are five pump stations form north to south. The temperature of the crude oil varies from $-10^{\circ} \mathrm{C}$ to $10^{\circ} \mathrm{C}$. The condensate water was formed on the pipeline from May to September in every year. The former anti-corrosive structure design was: $100 \mu \mathrm{m}$ zinc-rich epoxy primer and $100 \mu \mathrm{m}$ epoxy finishes. The corrosive problems are shown in fig 1 , which is just one year after the pipeline was put into operation. 


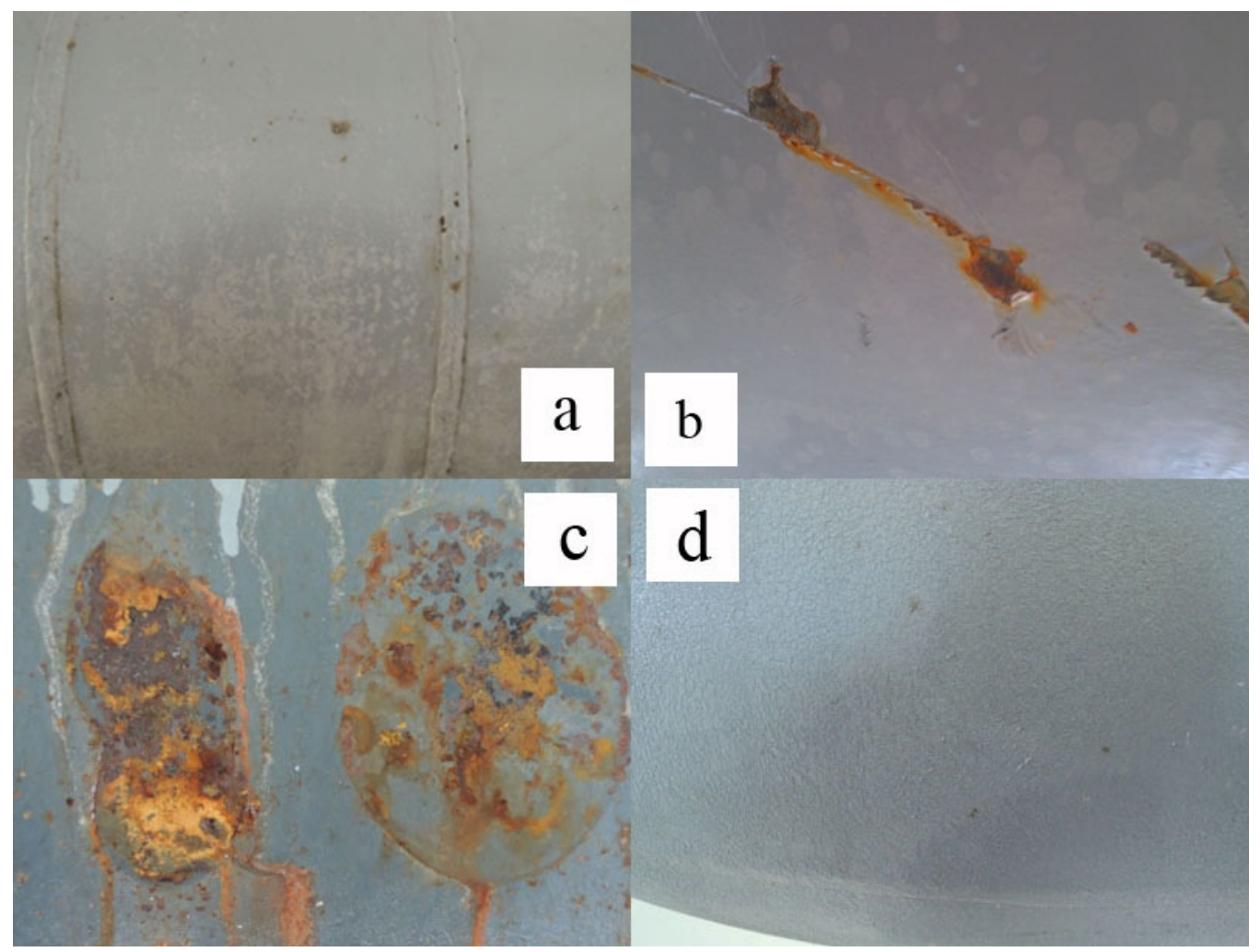

Fig. 1 the corrosive problems caused by condensed water (a. color changing, b. cracking, c. coming off, $d$. folding)

\section{The structure and property of the coating}

The anti-corrosive coating system in this article was made of three different functional coatings shown in fig 2 . They were $80 \mu \mathrm{m}$ cold zinc primer, $140 \mu \mathrm{m}$ micaceous iron oxide epoxy and $80 \mu \mathrm{m}$ superhydrophobic finishes.

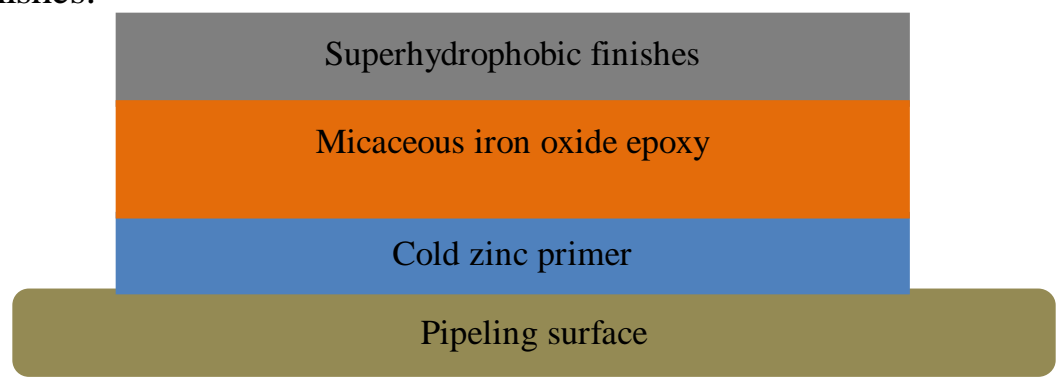

Fig. 2 the structure of the superhydrophobic \& anti-corrosive coating system

The cold zinc primer was one-component primer with dry film zinc content over $93 \%$. The spraying method is very simple because the primer is one-component. Also, the cathodic protection capability of the primer is much better than the zinc-rich epoxy primer due to relative high zinc content.

The intermediate coating is micaceous iron oxide epoxy. There is lots of mica pieces in the coating which can prevent the water penetrating deeper. Meanwhile, this coat can fit both the primer and finishes as intermediate coating.

The key coating is the superhydrophobic finishes, which play a decorative and functional role in the coating system. A two hierarchical Micro-Nano structure was formed on the intermediate coating by the superhydrophobic finishes shown in fig 3a. The Micro-Nano structure was mainly made of Nano- $\mathrm{SiO}_{2}$ by self-assembly way. The water contact angle (WCA) on the surface of the superhydrophobic finishes is about $153.7^{\circ}$ shown in fig $3 \mathrm{~b}$, which means that the water cannot attach to the pipeline. 


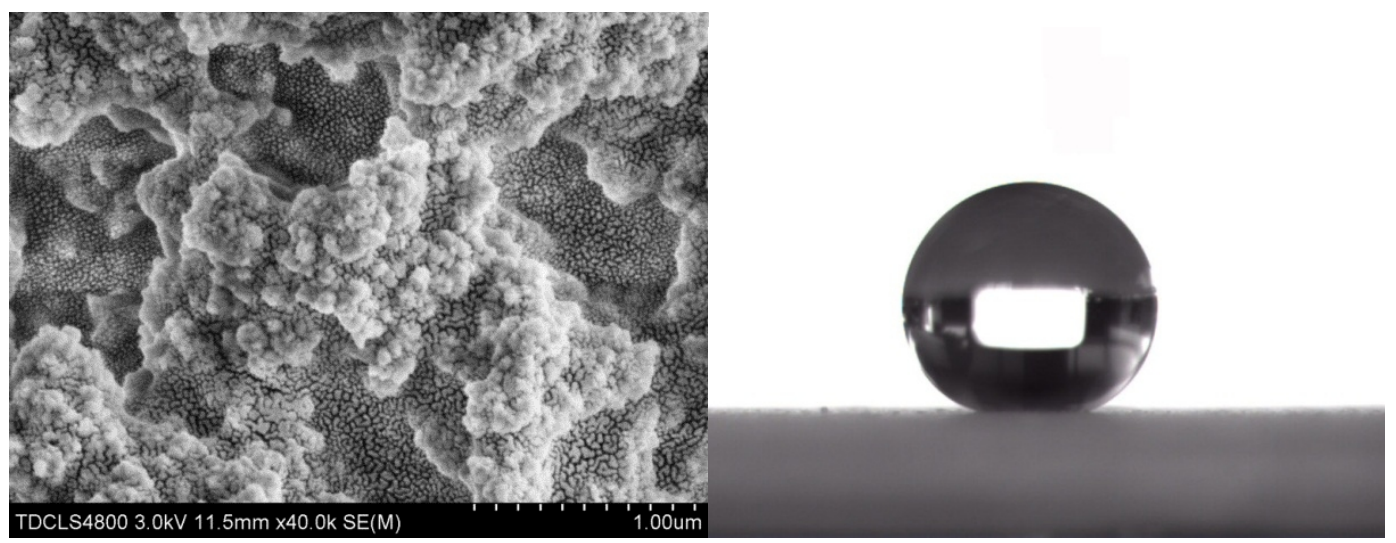

Fig.3 the SEM image (left) and WCA (right) of the superhydrophobic finishes

In this anti-corrosive coating system, the finishes can lower the condensate water attached to the pipeline; the intermediate can prevent the condensate water penetrating inner; the primer can give the system a much stronger cathodic protection capability.

\section{Application test}

The test location is in MoHe pump station in Da Hinggan Ling Prefecture. The coating process included polishing \&degusting, cleaning \& sweeping, primer coating, intermediate coating and finished coating shown in fig 4 in the order of a, b, c, d and e.

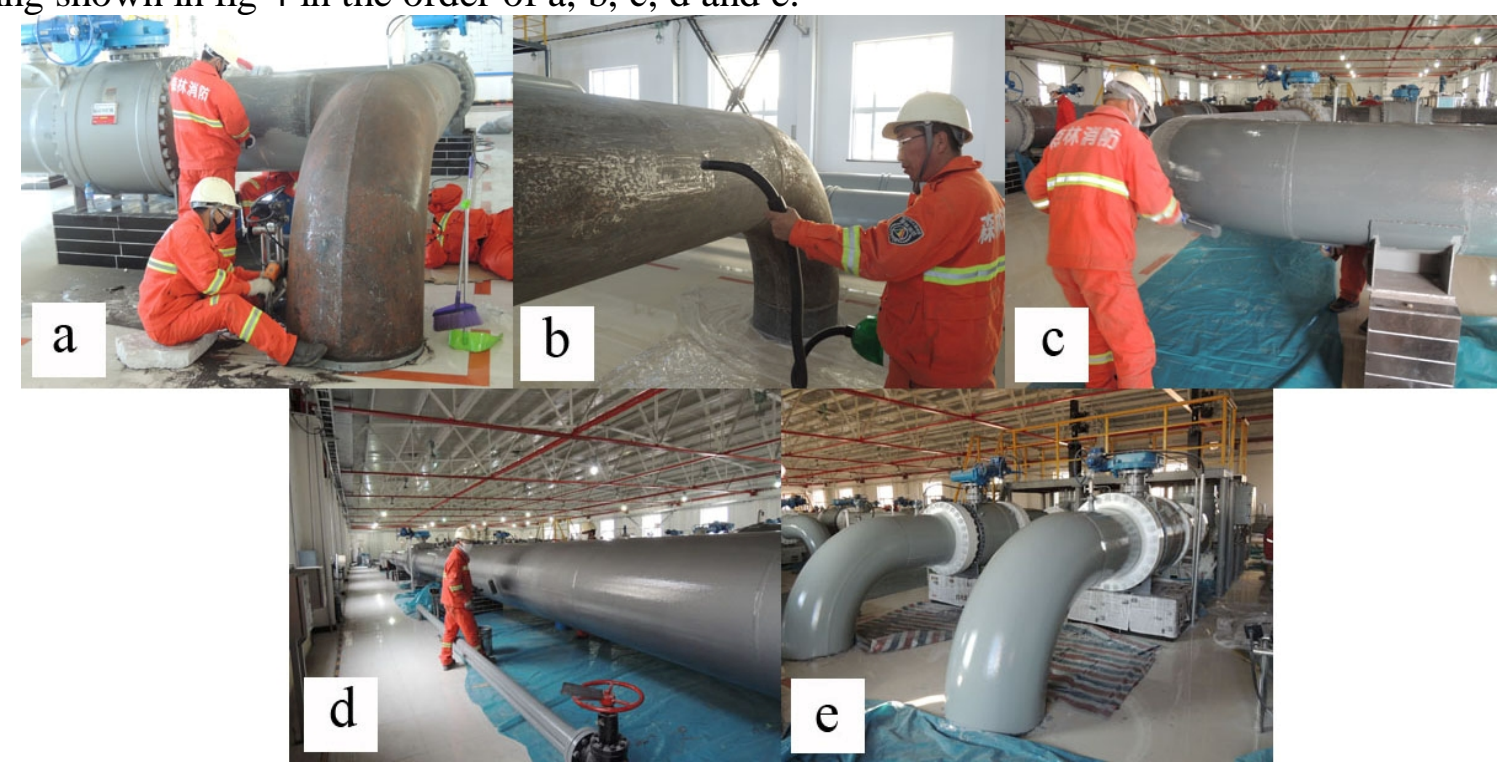

Fig.4 the coating process

After three years of condensate water immersing, the superhydrophobic anti-corrosive coating is intact as before. There is no coming off, color changing, folding, and cracking problems through naked eye shown in fig 5, which are found in the former coating usually.

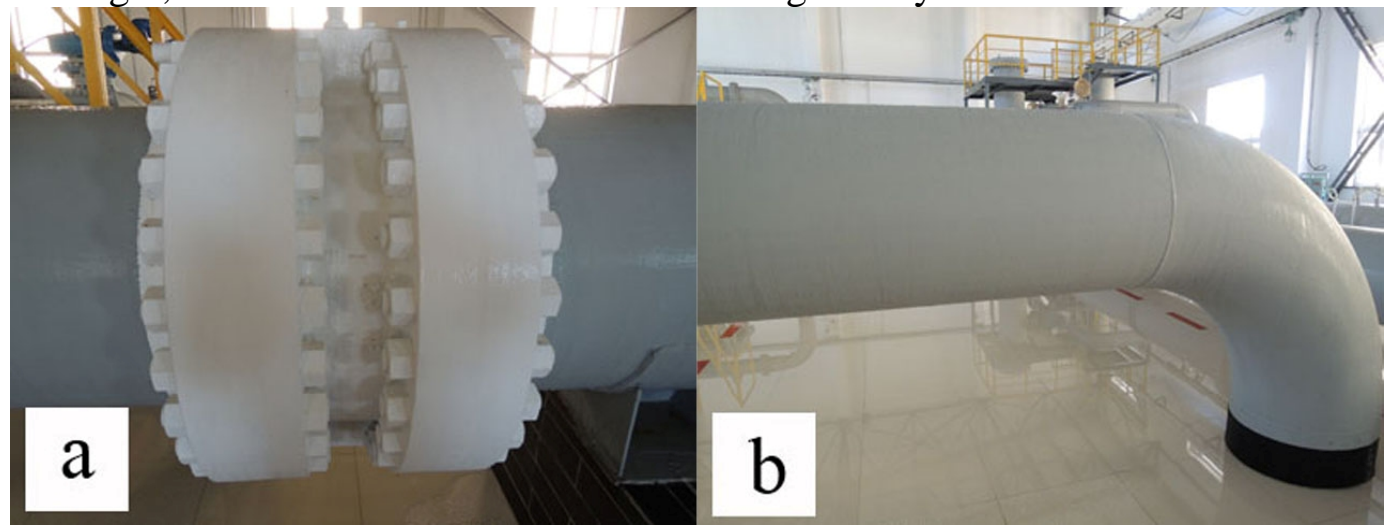

Fig.5 the test effect 


\section{Conclusion}

The superhydrophobic \& anti-corrosive coating system was made of three separate functional coating. The superhydrophobic finishes can greatly lower the amount of water attached to the pipeline, the micaceous iron oxide epoxy intermediate coating can shield water effectively, and the cold zinc primer can provide much stronger cathodic protection capability than zinc-rich epoxy primer. It has been proven that the superhydrophobic $\&$ anti-corrosive coating can fix out the corrosion problems caused by the condensate water by 3 years of testing.

\section{Acknowledgements}

This work was financially supported by the Petrochina Pipeline Company

\section{References}

[1] W Barthlott, C Neinhuis. Purity Of The Sacred Lotus, Or Escape From Contamination In Biological Surfaces. Planta, Vol. 202(1997), p. 1-8.

[2] TL Sun, L Feng, XF Gao. L Jiang, Bioinspired Surfaces With Special Wettability. Accounts of Chemical Research,Vol. 38(2005), p.644-652.

[3] XF Gao, L Jiang. Water-Repellent Legs Of Water Striders. Nature, Vol. 432 (2004), p.36-36.

[4] Y Wang, YF Mo, M Zhu, MW Bai. Wettability Of Metal Coatings With Biomimic Micro Textures. Surface and Coatings Technology, Vol.203(2008), p.137-141.

[5] SMM Ramos, A Benyagoub, B Canut, C Jamois. Superoleophobic Behavior Induced By Nanofeatures On Oleophilic Surfaces. Langmuir, Vol.26(2010), p. 5141-5146.

[6] J Gao, YL Liu, HP Xu, ZQ Wang, X Zhang. Mimicking Biological Structured Surfaces By Phase-Separation Micromolding. Langmuir, Vol. 25(2009), p.4365-4369.

[7] MA Raza,ES Kooij, A Silfhout, B Poelsma. Superhydrophobic Surfaces By Anomalous Fluoroalkylsilane Self-Assembly On Silica Nanosphere Arrays. Langmuir, Vol. 26(2010), p.12962-12972.

[8] Y Gao, CL He, YG Huang, FL Qing. Novel Water And Oil Repellent POSS-Based Organic/Inorganic Nanomaterial: Preparation, Characterization And Application To Cotton Fabrics. Polymer, Vol. 51(2010), p. 5997-6004.

[9] MY Yüce, AL Demirel, F Menzel. Tuning The Surface Hydrophobicity Of Polymer/Nanoparticle Composite Films In The Wenzel Regime By Composition. Langmuir, Vol.21(2005), p. 5073-5078.

[10] S Jindasuwan, O Nimittrakoolchai, P Sujaridworakun, S Jinawath, S Supothina. Surface Characteristics Of Water-Repellent Polyelectrolyte Multilayer Films Containing Various Silica Contents. Thin Solid Films, Vol.517(2009), p. 5001-5005.

[11] J Bravo, L Zhai, ZZ Wu, RE Cohen, MF Rubner. Transparent Superhydrophobic Films Based On Silica Nanoparticles. Langmuir, Vol.23(2007), p. 7293-7298.

[12] A Nakajima, K Abe K, Hashimoto, T Watanabe. Preparaton Of Hard Super-Hydrophobic Films With Visible Light Trasmission. Thin Solid Films, Vol.376(2000), p.140-143. 